\title{
ANALISA DAN PERANCANGAN DENGAN METODOLOGI BERORIENTASI OBYEK UNTUK SISTEM INFORMASI PENJUALAN SPAREPART MOBIL PADA HB. MOTOR
}

\author{
Fajar Erwindra Putra ${ }^{1)}$, Joko Sutrisno ${ }^{2)}$ \\ ${ }^{1}$ Sistem Informasi, Fakultas Teknologi Informasi, Universitas Budi Luhur \\ 1,2Jl. Raya Ciledug, Petukangan Utara, Kebayoran Lama, Jakarta Selatan 12260 \\ E-mail : fajarputra.bl@gmail.com ${ }^{1)}$,joko.sutrisno@budiluhur.ac.id ${ }^{2)}$
}

\begin{abstract}
Abstrak
HB. Motor merupakan sebuah instansi yang bergerak dibidang penjualan sparepart mobil. Dalam pengelolaan sistem penjualan sparepart di HB. Motor masih menggunakan proses manual dengan mencari berkas untuk memperoleh informasi bisnis yang ada. Dari sistem tersebut dapat memperlambat data menjadi kurang cepat dan tepat. HB. Motor belom memiliki sistem yang efesien untuk menyelesaiakan berbagai masalah yang terjadi seperti proses pengolahan data yang dilakukan oleh staf saat ini, masih memiliki beberapa kekurangan, diantaranya terjadi keterlambatan dalam menghasilkan informasi atau laporan, terjadi kesalahan data yang menyebabkan informasi yang dihasilkan tidak sesuai dengan kenyataan yang ada, maka penulis membuat penelitian ini bertujuan agar terciptanya sistem informasi yang efesien dan memudahkan mengkontrol pengolahan data. Metode yang digunakan studi litelatur, pengumpulan data, analisa sistem, Sistem ini menggunakan Microsoft Visual Studio 2008 dan MySQL. Dengan sistem tersebut diharapkan mempermudah transaksi dalam pelayanan serta pembuatan laporan, sehingga memperoleh kerja yang maksimal sehingga memperoleh informasi yang tepat.
\end{abstract}

Kata kunci: Sistem Informasi, Penjualan Sparepart, Microsoft Visual Studio

\section{PENDAHULUAN}

\subsection{Latar Belakang}

Penjualan merupakan suatu unsur penting dalam suatu badan usaha yang bergerak dalam bidang perdagangan, karena dalam penjualan suatu badan usaha berharap mendapat keuntungan untuk bisa melanjutkan usaha tersebut, karena itu diperlukan pelayanan yang selektif mungkin. Untuk mendukung kegiatan system penjualan yang tersistem agar dapat memperlancar serta memudahkan proses pengolahan data transaksi penjualan.

Penjualan merupakan kegiatan yang dilakukan oleh penjual dalam menjual barang atau jasa dengan harapan akan memperoleh laba dari adanya transaksi- transaksi tersebut dan penjualan dapat diartikan sebagai pengalihan atau pemindahan hak kepemilikan atas barang atau jasa dari pihak penjual ke pembeli.[1]

HB. MOTOR selaku usaha yang bergerak dibidang penjualan sparepart mobil secara tunai, tentunya melakukan proses pengolahan data agar dapat menghasilkan informasi yang dibutuhkan. Masalah pada HB.Motor diantaranya proses pengolahan data yang dilakukan oleh staf saat ini, masih memiliki beberapa kekurangan, diantaranya terjadi keterlambatan dalam menghasilkan informasi atau laporan, terjadi kesalahan data yang menyebabkan informasi yang dihasilkan tidak sesuai dengan kenyataan yang ada, Tidak adanya data retur sehingga sulit mengetahui jumlah sparepart yang diretur, Data surat jalan tidak tersedia sehingga sulit mengetahui nomor terakhir di surat jalan, karena masih jadi satu dengan nota penjualan, Pada saat proses penjualan sparepart staf sulit untuk mengetahui kondisi stok atau ketersediaan sparepart terupdate di gudang, hal ini menyebabkan proses pelayanan transaksi penjualan terhambat., Laporan yang dihasilkan sering terjadi keterlambatan disebabkan pencarian dokumen membutuhkan waktu yang lama Pengolahan data yang berjalan saat ini di HB. MOTOR bertujuan untuk menghasilkan informasi dan laporan mengenai hal-hal yang berhubungan dengan penjualan. Informasi maupun laporan yang dihasilkan dari proses pengolahan data yang saat ini berjalan diantaranya berupa informasi pembelian sparepart dan laporan penjualan sparepart.

Manfaat penulisan sistem informasi ini adalah Menciptakan sistem komputerisasi yang dapat memudahkan proses penjualan,Menciptakan efektivitas dan efisiensi dalam bekerja, Proses pembuatan laporan menjadi lebih cepat dan akurat, Masalah yang selama ini ada dalam proses penjualan akan teratasi dengan adanya penyimpanan data yang disimpan kedalam database.

\subsection{Penelitian Sebelumnya}

"Aplikasi Pembelian Dan Penjualan Barang Dagang Pada Cv Gemilang Muliatama Cikarang” 
bertujuan untuk membuat aplikasi sekaligus sebagai sistem informasi pembelian dan penjualan yang terintegrasi dengan database, guna memecahkan permasalahan-permasalahan yang ada dan untuk menunjang kinerja yang efektif dan efisien.[2]

"Perancangan Sistem Informasi Penjualan Sparepart Motor Pada CV. Lion” bertujuan untuk mempermudah proses kerja admin dalam mengelola data penjualan dan pelanggan mendapatkan informasi tentang sparepart yang dicari pada sistem. [3]

"Pengembangan Aplikasi Penjualan Dan Pembelian Bahan Bangunan Di Toko Bagja Jaya Menggunakan Metodologi Waterfall” bertujuan aplikasi yang dapat membantu dalam manajemen proses penjualan dan pembelian bahan bangunan.[4]

\section{METODE PENELITIAN}

a. Studi Literatur

Pada tahap ini dilakukan pencarian landasanlandasan teori yang diperoleh dari berbagai buku jurnal dan juga internet untuk melengkapi perbendaharaan konsep dan teori, sehingga memiliki landasan dan keilmuan yang baik dan sesuai.

b. Pengumpulan Data

Pada tahap ini dilakukan proses pengumpulan data dengan metode wawancara dan observasi untuk melakukan pengamatan dan analisa terhadap proses yang sedang berjalan, sehingga mendapatkan data dan informasi yang dibutuhkan oleh peneliti.

c. Analisis Sistem

Pada tahap ini dilakukan identifikasi masalah pada sistem yang sedang berjalan. Dengan demikian, diharapkan peneliti dapat menemukan kendalakendala dan permasalahan yang terjadi, sehingga peneliti dapat mencari solusi dari permasalahan tersebut.

d. Pengembangan Sistem

Pada Tahap ini dilakukan Pengembangan sistem dengan menggunakan Metode Waterfall

Gambar 1. Model Waterfall
Gambar 1 adalah metode yang digunakan penulis untuk pengembangan sistem yang terdapat analisa, design, implementasi, testing dan maintenance.

\section{HASIL DAN PEMBAHASAN}

3.1. Activity Diagram

a. Proses Penjualan Sparepart

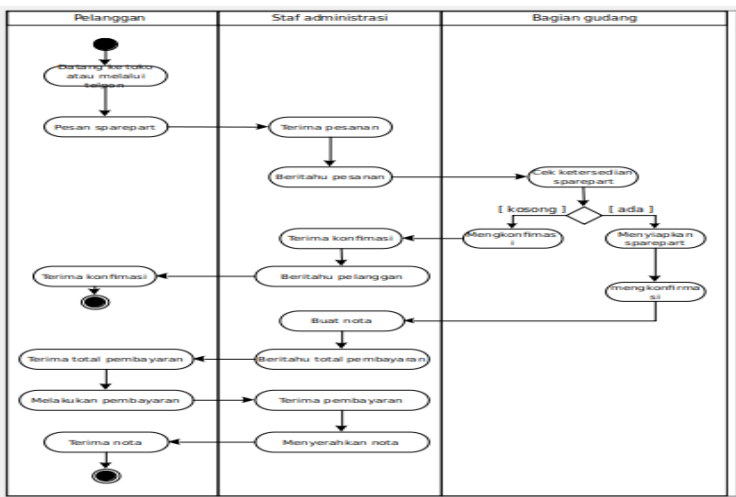

Gambar 2. Activity Diagram Proses Penjualan Sparepart

Gambar 2 merupakan activity diagram proses penjualan sparepart terdapat 3 actor yaitu pelanggan, staff administrasi dan staff gudang. Dengan proses dimulai ketika pelanggan memesan Sparepart yang akan dibeli dengan cara datang langsung atau melalui telpon, untuk pemesanan yang melalui telpon biasanya pelanggan yang sudah menjadi langganan tetap dan pembelian dalam jumlah besar, staf administrasi akan memberitahu pesanan ke bagian gudang untuk mengecek Sparepart yang dipesan, apabila tidak tersedia staf administrasi akan mengkonfirmasikan kepada pelanggan bahwa Sparepart saat ini sedang kosong. Apabila Sparepart tersedia bagian Gudang akan menyiapkan Sparepart dan staf administrasi akan konfirmasi ke pelanggan untuk membuat nota dan pelanggan membayar sesuai harga total Sparepart yang dipesan kemudian staf administrasi akan menyerahkan nota sebagai bukti pemesanan dan pembayaran.

b. Proses Penjualan Sparepart Eceran

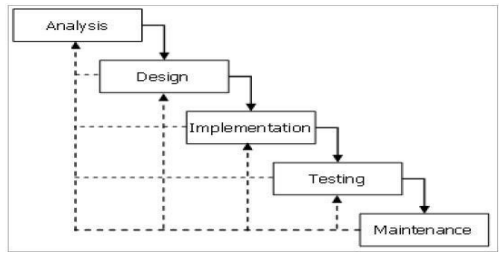




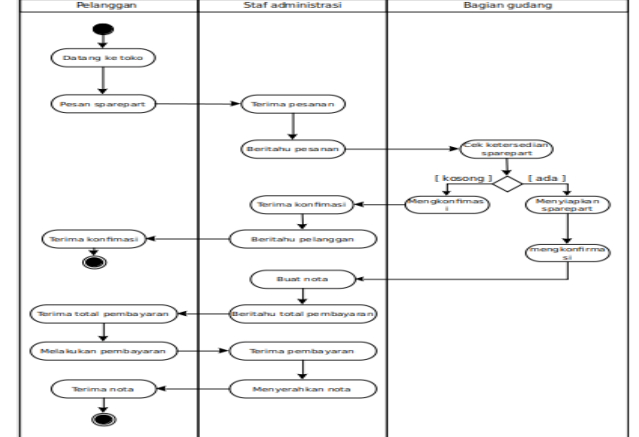

Gambar 3. Activity Diagram Proses Penjualan Eceran

Gambar 3 merupakan activity diagram proses penjualan eceran terdapat 3 actor yaitu pelanggan, staff administrasi dan staff gudang dengan proses HB.MOTOR melayani juga penjualan dengan eceran untuk pelanggan yang hanya membeli Sparepart sesekali saja dan dalam jumlah kecil, pelanggan yang akan membeli Sparepart datang langsung ke tempat, lalu menanyakan Sparepart yang akan di beli, staff administrasi menyiapkan Sparepart, pelanggan membayar Sparepart lalu dibuatkan nota, nota diserahkan ke pelanggan.

c. Proses Pengiriman Sparepart

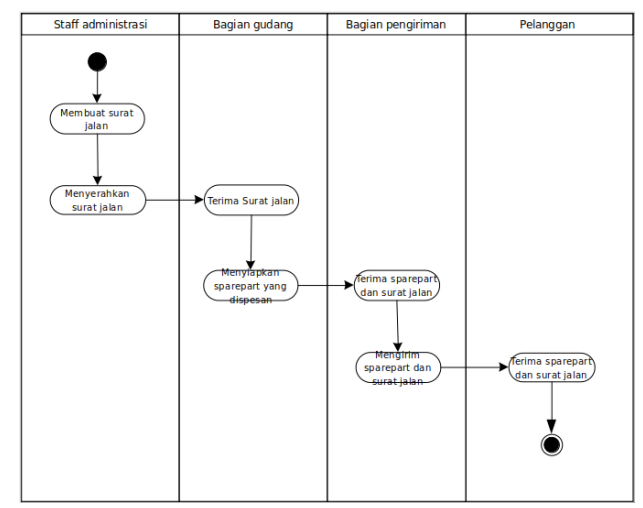

Gambar 4. Activity Diagram Proses Pengiriman Sparepart

Gambar 4 merupakan activity diagram proses pengiriman sparepart terdapat 4 actor yaitu pelanggan, staff administrasi, bagian pengiriman dan staff gudang dengan proses Pengiriman Sparepart hanya untuk pelanggan tetap yang membeli Sparepart dalam jumlah besar, Setelah konsumen melakukan pembayaran, Staf Administrasi membuatkan Surat Jalan dan menyerahkannya ke bagian gudang untuk disiapkan Sparepartnya. Setelah Sparepart sudah siap bagian Gudang akan menyerahkan surat jalan ke bagian pengiriman kemudian bagian pengiriman akan mengirimkan Sparepart kepada pelanggan.

d. Proses Retur

Pelanggan mengecek sparepart dalam kondisi bagus atau rusak, apabila rusak pelanggan mengajukan retur. Staff pengiriman mencatat retur di surat jalan lalu menyerahkan ke staff administrasi, staff administrasi mengecek surat jalan dan menyerahakannya ke staff gudang, kemudian staff gudang menyiapkan sparepart dan menyerahkan ke staff pengiriman, lalu staff pengiriman mengirim sparepart ke pembeli.

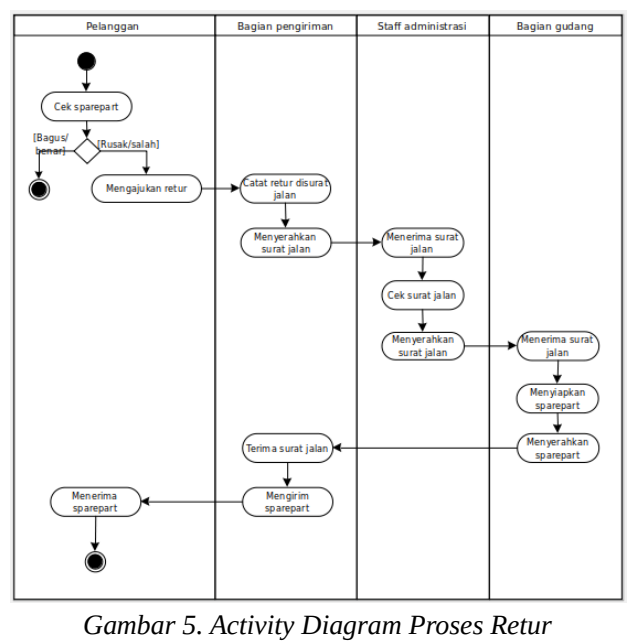

Gambar 5 merupakan activity diagram proses return terdapat 4 actor yaitu pelanggan, staff administrasi, bagian pengiriman dan staff gudang

e. Proses Pembuatan Laporan

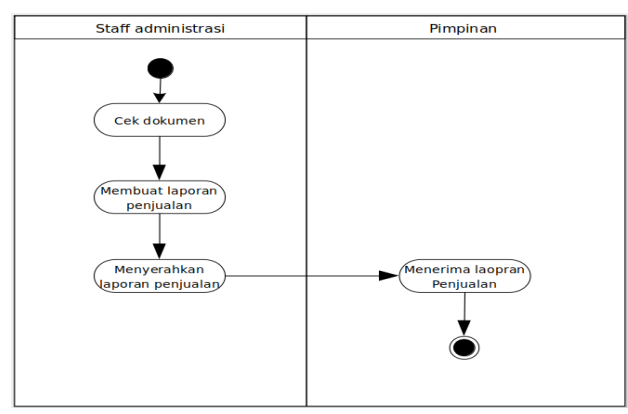

Gambar 6. Activity Diagram Proses Pembuatan Laporan

Gambar 6 adalah alur pembuatan laporan berdasarkan dokumen, staff administrasi membuat laporan penjualan dan menyerahkan kepada pemilik. 


\subsection{Fishbond Diagram}

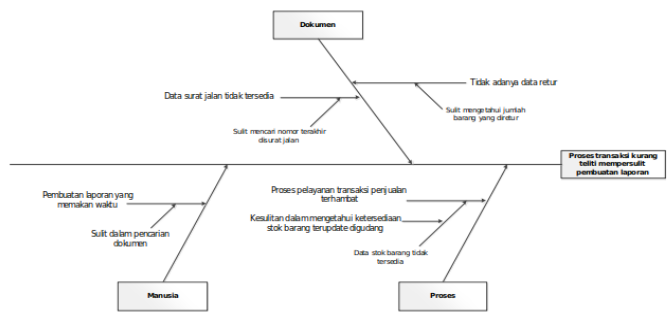

Gambar 7. Fishbond Diagram

Gambar 7 adalah gambar fishbond yang berisi masalah dan solusi yang terjadi pada HB. Motor.

\subsection{Use case}

a. Usecase Master

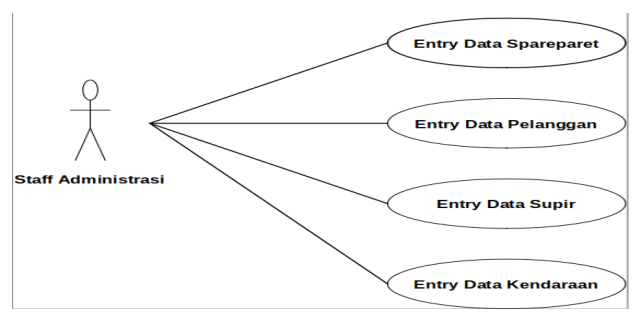

Gambar 8. Use Case Diagram Master

Gambar 8 terdapat 1 actor yaitu staff administrasi yang dapat entry data sparepart, entry pelanggan, entry supir, dan entry kendaraan.

b. Usecase Transaksi

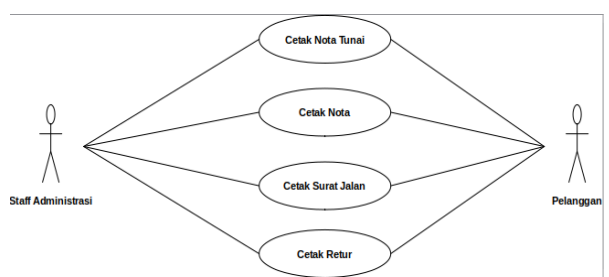

Gambar 9. Use Case Diagram Transaksi

Gambar 9 terdapat 2 actor yaitu staff administrasi dan pelanggan. Yang berisi cetak nota tunai, cetak nota, cetak kartu, cetak retur.

c. Usecase Laporan

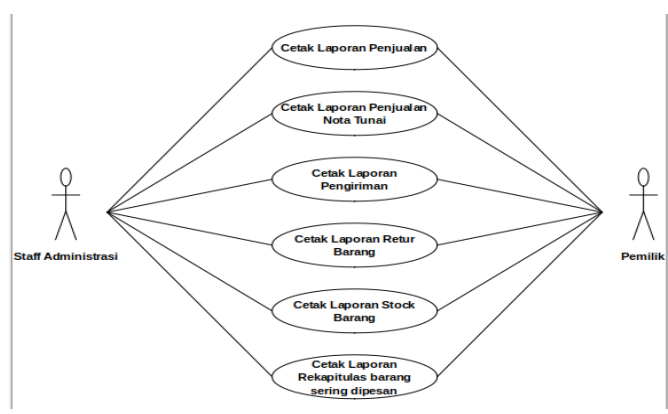

Gambar 10. Use Case Diagram Package Laporan

Gambar 10 menjelaskan tentang staff administrasi membuat laporan yang akan dikirim ke pemilik setiap bulan.

\subsection{Logical Record Structure}

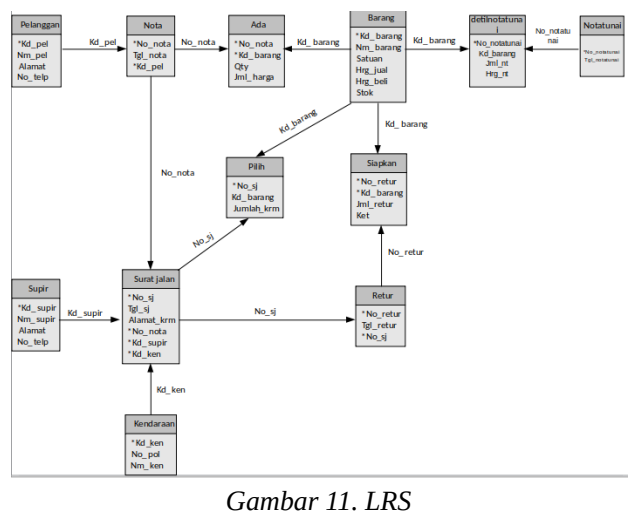

Gambar 11 adalah logical record structure yang berisi database sistem yang saling terhubung.

\subsection{Struktur Tampilan}

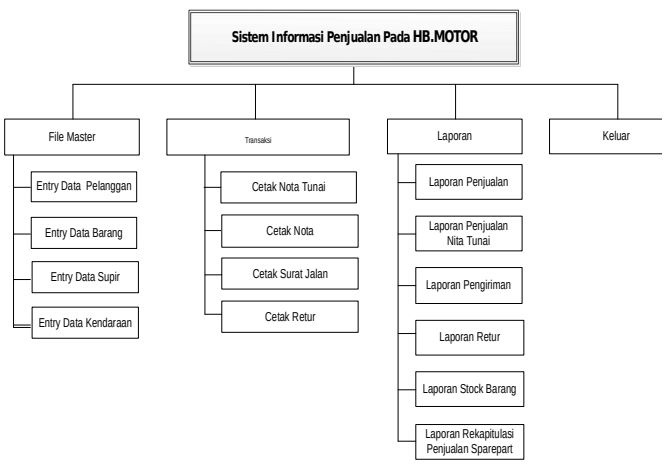

Gambar 12 berisi bagian sistem yang terdapat file master, transaksi, laporan, keluar.

\subsection{Rancangan Layar}

a. Tampilan Menu Transaksi 


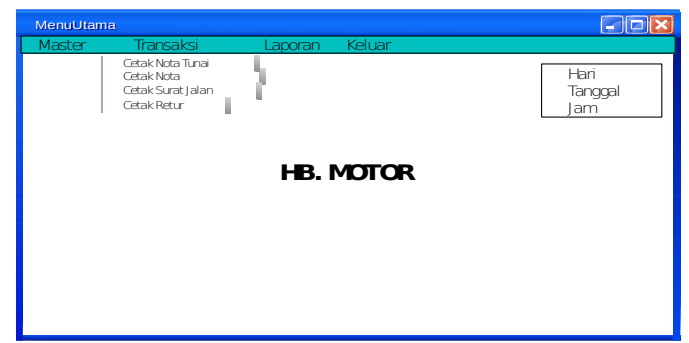

Gambar 13. Tampilan Menu Transaksi

Gambar 13 merupakan tampilan menu transaksi yang berisi cetak nota tunai,cetak nota, cetak surat jalan, cetak retur.

b. Form Surat Jalan

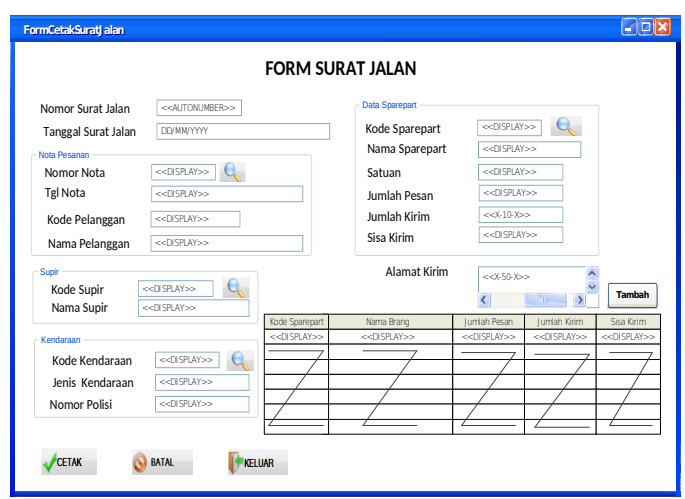

Gambar 14. Form Surat Jalan

Gambar 14 merupakan tampilan dari form surat jalan yang berisi no surat, tanggal surat dll.

c. Laporan Cetak Retur

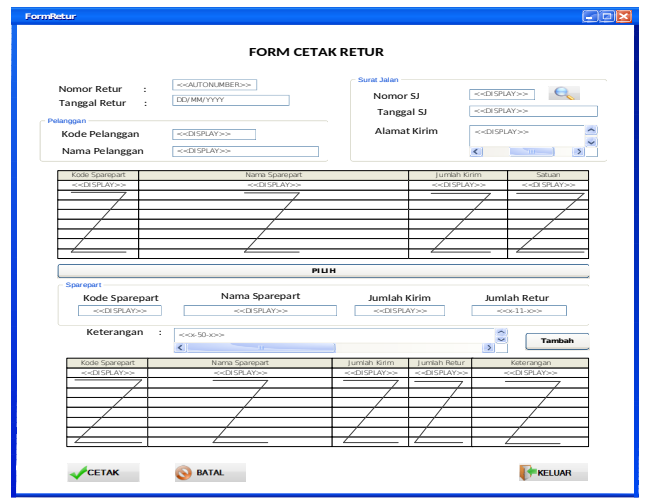

Gambar 15. Laporan Cetak Retur

Gambar 15 merupakan tampilan dari form cetak retur.

d. Sistem Keluaran Stok Sparepart

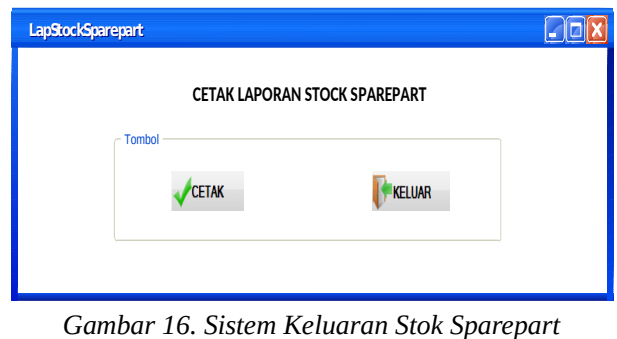

Gambar 16 merupakan tampilan dari form cetak retur yang berisi mengenai stok barang.

\section{KESIMPULAN}

Berdasarkan pembahasan penelitian penulis dapat menyimpulan yaitu:

a. Merancang sistem informasi yang menerapkan standarisasi pengolahan data yang sesuai kebutuhan sehinggam meminimalisir kesalahan dalam pencatatan data, transaksi dan pembuatan laporan, seperti dibuatkannya modul cetak retur sehingga mempunyai dokumen tersendiri dan laporan retur untuk mengetahui sparepart yang diretur.

b. Proses penyimpanan data dalam jumlah besar sudah dapat teratasi dengan adanya database yang digunakan oleh sistem yang ada.

c. Dengan sistem yang telah terkomputerisasi, disedikan fitur update stok otomatis pada saat proses penjualan sparepart dan disediakan juga modul cetak laporan stok sparepart terupdate sehinggan proses pelayanan penjualan sparepart dapat dilakukan secara lebih cepat, tepat, akurat dan efisien.

\section{DAFTAR PUSTAKA}

[1] Badii, Y. A. and Kuncoro, D. Perancangan Sistem Informasi Penjualan Dan Bembelian Serta Pengendalian Stok Barang Pada Toko Batik Kusumawardani Solo. Jurnal Teknologi Informasi dan Ilmu Komputer (JTIIK), Vol 23(1), 2017 pp. 1926.

[2] Imroatus Sholikhah., Mahmud Sairan., Nurvia Oktaviani Syamsiah.. Aplikasi Penjualan dan Pembelian sparepart pada CV Gemilang Muliatama. Jurnal Teknik Komputer AMIK BSI, Vol. III(1), 2017, pp. 16-23.

[3] Yosep Yordan Mehdila, Darman Umagapi. Perancangan Sistem Informasi Penjualan Sparepart Motor Pada CV. LION. Indonesian Journal on Information System, Vol 1(1), 2016, pp 39-46.

[4] Acep Angga , Bunyamin. Pengembangan Aplikasi Penjualan Dan Pembelian Bahan Bangunan Di Toko 
Bagja Jaya Menggunakan Metodologi Waterfall. Jurnal algoritma, Vol12(1), 2015, pp 1-6. 